\title{
Randomised controlled trials of phenobarbitone and valproate in febrile convulsions
}

\author{
R W NEWTON
}

Department of Neurology, Royal Manchester and Booth Hall Children's Hospitals, Manchester

SUMMARY Results from British trials of phenobarbitone and valproate for the prophylactic treatment of febrile convulsions were pooled and analysed on an intention to treat basis. The overall odds ratio for phenobarbitone was 0.8 and for valproate 1.42 . Neither result was significant. Neither treatment can be recommended in the light of experience.

Controlled trials of drug treatment are usually pragmatic studies of treatment practice, and analysis should then be on an intention to treat basis. The question being asked is whether the intention to treat a population of children with febrile fits with anticonvulsants reduces the risk of recurrence relative to that in a control group. Many trials have excluded children from analysis who did not take their medication through either poor adherence to instructions or side effects. Analysis on this basis answers the question of whether risk of recurrence is reduced in quite a selected population which is difficult to define in advance.

Analysis on an intention to treat basis demands that children are analysed with the group to which they were originally allocated. Invariably some children are lost to follow up and available resources make this difficult to overcome. An assumption is usually made in the analysis that no bias has been introduced through this happening. Studies have shown apparently conflicting results. This is often due to small study groups either exaggerating or overlooking clinical benefit due to the play of chance. Pooled analysis leaves less to the play of chance by increasing the study population size. The method used is similar to that used in multicentre trials. Within centre differences between study and control groups become within study differences that are estimated and then pooled. An overall odds ratio (relative risk) is provided. This is the risk of recurrence in the treatment group relative to controls. An odds ratio of unity thus will signify no difference. An odds ratio of less than unity suggests some treatment benefit; greater than unity no benefit. When the odds ratio and its $95 \%$ confidence interval lie entirely to one side of unity the result is significant at $\mathrm{p}<0.5$.
The method assumes data from all trials are available. None must be omitted because they showed negative results and were therefore unpublished. The method does not assume that one trial is directly comparable with another, but does assume the true odds ratio to be the same for each.

\section{Method}

Statistical analysis was identical to that used by Collins et al. ${ }^{1}$ Six British trials of phenobarbitone ${ }^{2} 35-8$ were identified and four of valproate. ${ }^{4} 6-8$ The table summarises data from the trials.

Trials were identified through a computerised literature search. Those unpublished were identified by writing to all members of the British Paediatric Neurology Association and paediatricians known to have participated in such work.

Children were reallocated to the groups to which they were originally assigned before reanalysis of data. Details were usually available from the paper itself or clarification was sought from the authors. Data in all but one paper can be confirmed. ${ }^{7}$

\section{Results}

The numbers in each trial and recurrences in each study group are summarised in the table. The pooled analysis of the phenobarbitone and valproate trials is summarised in the figure.

For phenobarbitone the odds ratio varied from $0.42^{6}$ to $2 \cdot 07^{7}$ : in two it was less than unity and in four greater. The overall odds ratio for the 535 children was 0.8 ( $95 \%$ confidence interval: 0.53 to $1 \cdot 20)$ a non-significant result. Sixty six of the 296 $(22 \%)$ treated children had recurrences compared with 58 of $236(25 \%)$ controls. 
Table Characteristics of randomised controlled British trials of phenobarbitone or valproate, or both, in febrile convulsions

\begin{tabular}{|c|c|c|c|c|c|c|}
\hline \multirow[t]{2}{*}{$\begin{array}{l}\text { Study } \\
\text { (reference) }\end{array}$} & \multirow[t]{2}{*}{$\begin{array}{l}\text { Age on } \\
\text { entry }\end{array}$} & \multirow[t]{2}{*}{$\begin{array}{l}\text { Follow up } \\
\text { period }\end{array}$} & \multicolumn{2}{|c|}{$\begin{array}{l}\text { No of patients } \\
\text { followed up }\end{array}$} & \multicolumn{2}{|c|}{$\begin{array}{l}\text { No of recurrent } \\
\text { febrile convulsions }\end{array}$} \\
\hline & & & Treated & Control & Treated & Control \\
\hline \multicolumn{7}{|c|}{ Phenobarbitone trials } \\
\hline 2 & 6 months- -3 years & 6 months & 88 & 73 & 10 & 14 \\
\hline 3 & 6 months -4 years & 6 months & 51 & 10 & 14 & 2 \\
\hline 5 & $<24$ months & 12 months & 50 & 45 & 10 & $1 \overline{5}$ \\
\hline 6 & 6-18 months & Mean of 13.5 months & 23 & 21 & 4 & 7 \\
\hline 7 & 6-42 months & 24 months & 43 & 27 & 16 & 6 \\
\hline 8 & $6-72$ months & Mean of 30 months & 41 & 60 & 12 & 14 \\
\hline Overall & & & 296 & 236 & 66 & 58 \\
\hline \multicolumn{7}{|c|}{ Valproate trials } \\
\hline 4 & 6 months -6 years & 12 months & 30 & 28 & 8 & 9 \\
\hline 6 & 6 months -6 years & Mean of 13.5 months & 20 & 21 & 1 & 7 \\
\hline 8 & 6 months -6 years & Mean of 30 months & 50 & 60 & 20 & 14 \\
\hline \multicolumn{3}{|l|}{ Overall } & 145 & 136 & 49 & 36 \\
\hline
\end{tabular}

Plasma drug concentrations were measured in each trial except that of Bacon et al which measured salivary concentrations.

With valproate the odds ratio varied from $0 \cdot 11^{6}$ to $2 \cdot 8,{ }^{7}$ in two it was less than unity and in two greater. The overall odds ratio was $1.42(95 \%$ confidence interval: $0 \cdot 85$ to $2 \cdot 36$ ), also a non-significant result. Forty nine of $145(34 \%)$ treated children had recurrences compared with 36 of $136(26 \%)$ controls.

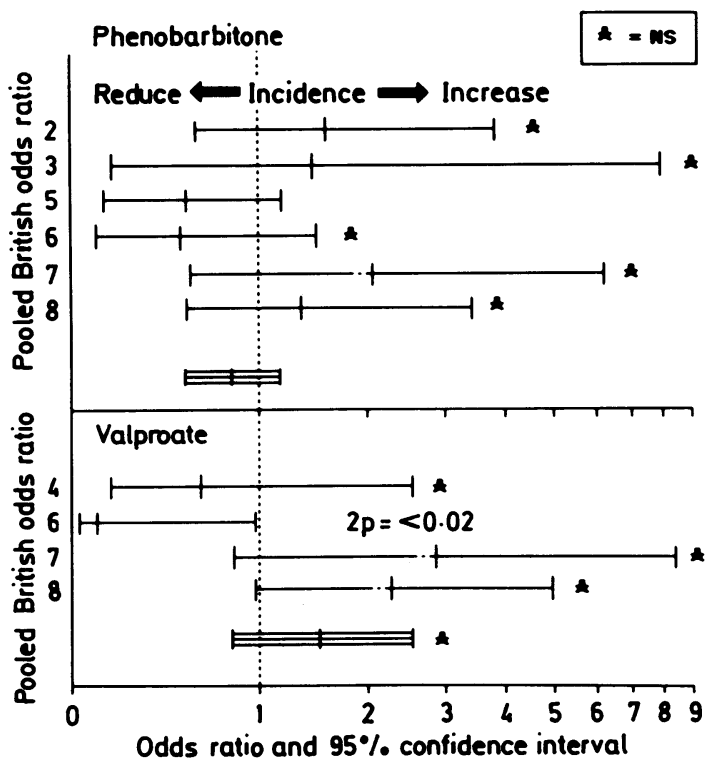

Figure Pooled odds ratio of recurrent fit in randomised controlled trials of phenobarbitone and valproate, with $95 \%$ confidence limits.

\section{Discussion}

Only the British experience has been considered as the logistic problems in identifying unpublished trials showing negative results on a world basis seemed insurmountable. The analysis shows well how small study groups serve to exaggerate benefits or drawbacks of treatment. All the trials have been too small for paediatricians to use their findings with confidence.

Pooled analysis of the British experience fails to show any overall value in deciding to treat children who have febrile convulsions with anticonvulsants. The results do suggest that phenobarbitone might prevent as many as half the recurrences but they establish that any benefit from valproate is likely to be unacceptably small.

The overall risk of recurrence is $26 \%$. If the odds ratio of $\mathbf{0 . 8}$ for phenobarbitone trials were significant one would have to give anticoagulants to 100 children to stop five having a recurrence.

With side effects reported in up to $40 \%$ of the treated group it must be concluded that prophylactic treatment for febrile convulsions cannot be recommended. Alternative methods of treatment must be assessed such as the administration of rectal diazepam in those particularly at risk of recurrence. Meanwhile clear advice to parents on the first aid management of a seizure and how to gain access to medical care remain most important.

I would like to thank the members of the British Paediatric Neurology Association and Drs Doug Addy, John Williams, and 
Chris Bacon for their help, and Mrs Margaret Cunnah for typing the manuscript.

\section{References}

1 Collins R, Yusuf S, Peto R. Overview of randomised trials of diuretics in pregnancy. $\mathrm{Br}$ Med $J$ 1985;290:17-23.

${ }^{2}$ Heckmatt JZ, Houston AB, Stephenson JBP, Dodd KL, Lealman GT, Loga RW. Failure of phenobarbitone to prevent febrile convulsions. Br Med J 1976;i:559-61.

3 Addy DP. Febrile convulsions. In: Roberts FD, ed. Tegretol in epilepsy. Proceedings of an International Meeting. Macclesfield: Geigy Pharmaceuticals, 1977:4-7.

${ }^{4}$ Williams AJ, Evans-Jones LG, Kindley AD, Groom PJ. Sodium valproate in the prophylaxis of simple febrile convulsions. Clin Pediatr (Phila) 1979;18:426-30.

5 Bacon CJ, Mucklow JC, Rawlins MD, Hierons AM, Webb JKG, Weightman D. Placebo controlled study of phenobarbitone and phenytoin in the prophylaxis of febrile convulsions. Lancet 1981 ;ii:600-4.

${ }^{6}$ Ngwane E, Bower B. Continuous sodium valproate or phenobarbitone in the prevention of 'simple' febrile convulsions. Arch Dis Child 1980;55:171-4.

7 Wallace S, Aldridge Smith J. Successful prophylaxis against febrile convulsions with valproic acid or phenobarbitone. $\mathrm{Br}$ Med J 1980;280:353-4.

$\checkmark$ McKinlay IA, Newton RW. Failure of intention to treat children with febrile fits with phenobarbitone or valproate to prevent recurrence. Presented to North of England Neurology Association Spring 1981 and Paediatric Research Society, Autumn 1981. Dev Med Child Neurol (in press).

Correspondence to Dr RW Newton, Department of Neurology, Royal Manchester Children's Hospital, Pendlebury M27 1HA.

Accepted 22 March 1988 